\title{
Optopharmacological control of TRPC channels by coumarin-caged lipids is associated with a phototoxic membrane effect
}

\author{
Oleksandra Tiapko ${ }^{1}$, Bernadett Bacsa ${ }^{1 *}$, Gema Guedes de la $\mathrm{Cruz}^{2}$, Toma Glasnov ${ }^{2}$ \\ $\&$ Klaus Groschner ${ }^{1 * *}$ \\ ${ }^{1}$ Institute of Biophysics, Medical University of Graz, BioTechMed-Graz, Harrachgasse 21, Graz, 8010, Austria; \\ ${ }^{2}$ Institute of Chemistry, University of Graz, NAWI Graz, BioTechMed-Graz, Heinrichstrasse 28, Graz, 8010, Austria
}

Received May 6, 2015; accepted June 6, 2016; published online July 15, 2016

\begin{abstract}
Photouncaging of second messengers has been successfully employed to gain mechanistic insight of cellular signaling pathways. One of the most enigmatic processes of ion channel regulation is lipid recognition and lipid-gating of TRPC channels, which represents pivotal mechanisms of cellular $\mathrm{Ca}^{2+}$ homeostasis. Recently, optopharmacological tools including caged lipid mediators became available, enabling an unprecedented level of temporal and spatial control of the activating lipid species within a cellular environment. Here we tested a commonly used caged ligand approach for suitability to investigate TRPC signaling at the level of membrane conductance and cellular $\mathrm{Ca}^{2+}$ handling. We report a specific photouncaging artifact that is triggered by the cage structure coumarin at UV illumination. Electrophysiological characterization identified a light-dependent membrane effect of coumarin. UV light $(340 \mathrm{~nm})$ as used for photouncaging, initiated a membrane conductance specifically in the presence of coumarin as low as $30 \mu \mathrm{mol} \mathrm{L}{ }^{-1}$ concentrations. This conductance masked the TRPC 3 conductance evoked by photouncaging, while TRPC-mediated cellular $\mathrm{Ca}^{2+}$ responses were largely preserved. The observed light-induced membrane effects of the released caging moiety may well interfere with certain cellular functions, and prompt caution in using coumarin-caged second messengers in cellular studies.
\end{abstract}

caged diacylglycerols, TRPC channels, $\mathrm{Ca}^{2+}$ signaling, optopharmacology

Citation: Tiapko, O., Bacsa, B., de la Cruz, G.G., Glasnov, T., and Groschner, K. (2016). Optopharmacological control of TRPC channels by coumarin-caged lipids is associated with a phototoxic membrane effect. Sci China Life Sci 59, 802-810. doi: 10.1007/s11427-016-5095-5

\section{INTRODUCTION}

Diacylglycerol (DAG) is an important and multifunctional second messenger, which plays a key role in signal transduction. The release of this regulatory lipid is controlled by phospholipase $\mathrm{C}$ driven hydrolysis of phosphatidylinositol 4,5-bisphosphate (PIP2) (Ohanian and Ohanian, 2001). The best recognized and characterized function of DAG is to activate the protein kinase $\mathrm{C}$ family (PKC) by interacting with their C1 domains (Newton, 2010). Moreover, DAG

*Corresponding author (email: bernadett.bacsa@medunigraz.at) **Corresponding author (email: klaus.groschner@medunigraz.at) controls activation and translocation of other proteins including chimaerins, RasGRPs, Munc13 and DGK $\gamma$ (Yang and Kazanietz, 2003).

The first evidence that exogenous DAG directly activates a subset of human transient receptor potential canonical channels (TRPC2/3/6/7) in a PKC-independent manner was shown already back in 1999 (Hofmann et al., 1999, Lucas et al., 2003). TRPC $3 / 6 / 7$ channels are mammalian homologues of light sensitive Drosophila TRP channels and are widely distributed in the central nervous system, kidney, digestive tract and blood vessels (Fu et al., 2015). These channels are classified as non-selective cation channels, which favor transport of $\mathrm{Ca}^{2+}$ over other cations (Kamouchi et al., 1999). 
A potential DAG-sensing TRP_2 domain in the N-terminus of TPRC3 channels was identified utilizing computational analysis of amino acid sequences and mutagenesis experiments (van Rossum et al., 2008). However, the molecular basis of the lipid sensing machinery that enables recognition of lipid metabolites through specific lipid-TRPC interactions is still unclear. Major problems arise during characterization of TRPC-DAG interaction due to lack of experimental methods to measure local concentrations of the lipid ligand and difficulties to detect binding between lipid and integral membrane proteins.

Photoactivatable (caged) second messengers are considered as valuable tools to analyze signal transduction processes, and this approach has been successfully employed to study lipid-mediated signaling pathways (Subramanian et al., 2010; Mentel et al., 2011). In caged second messengers, the biological activity of the synthetic molecules is "masked" with a photoremovable protecting (caging) group. After equilibration of the inactive precursor molecule such as a caged diacylglycerol at its target, exposure to light with suitable wavelength initiates rapid and quantitative release of the messenger. This optopharmacological process enables highly efficient temporal and spatial control of the active ligand concentrations and localization in isolated cells and also in multicellular preparations as well as in vivo. Thus, phototriggered uncaging of lipid mediators appears as an attractive technology for molecular, mechanistic studies as well as for pharmacological screening tasks. The caged lipid approach is currently considered to improve the existing understanding of lipid pharmacology and is thus a unique path to decipher the exact molecular mechanism of lipid sensing ion channels (Höglinger et al, 2014). Of note, caged lipids typically enable highly efficient delivery of the lipid to its cellular target. A prerequisite for suitability of such approaches is that the caged compound as well as the caging molecule is inert in terms of membrane and cell functions. Designing a caged lipid involves the selection of a suitable orthogonal protecting group that can be removed by light. Nowadays, plethora of such groups are available to choose from (Goeldner and Givens, 2005; Pelliccioli and Wirz, 2002). However, to generate a caged lipid, nitrobenzyl (Huang et al., 1996) and coumarin derivatives evolved as preferred molecules (Furuta et al., 1999; Suzuki et al., 2003). Coumarins (two-photon cages), being the newer generation of photocages, possess better photophysical properties-red-shifted absorption spectra, higher quantum yields and extinction coefficients, and are presently the preeminent choice in lipid caging (Givens et at., 2012).

Recent functional studies with caged DAGs suggest significant structural specificity of the DAG effects on TRPC3/6 channels and support a direct lipid-ligand gating process (Nadler et al., 2013).

In the present study, we evaluated 6-bromo-7-hydroxycoumarin-4-ylmethoxycarbonyl phototriggered 1,2-di- $O$ octanoyl glycerol (Bhcmoc-1,2-DOG) release and its effects on TRPC3-mediated $\mathrm{Ca}^{2+}$ signaling and impact on membrane conductance. After phototriggered uncaging, the free 1,2-di-O-octanoyl glycerol (1,2-DOG) elicited $\mathrm{Ca}^{2+}$ transients specifically in TRPC3 overexpressing HEK293 cells. However, our detailed electrophysiological analysis revealed that upon photolysis, the 4-hydroxymethyl-6-bromo7-hydroxycoumarin (Bhc) cage itself causes distinct membrane conductance artifacts. Our results prompt for particular caution in the interpretation of data obtained by use of coumarin-caged diacylglycerols.

\section{RESULTS}

\section{Synthesis of Bhcmoc-1,2-DOG}

The synthesis of Bhcmoc-1,2-DOG is straightforward and follows already known synthetic paths (Figure 1).

In an attempt to make the previously reported preparation protocol (Hagen et al., 2010; Hess et al., 2007; Kim et al., 2011; Nadler et al., 2013; Tsien et al., 2000) more efficient, we have performed the initial two synthetic steps using sealed vessel controlled microwave heating. For the initial condensation step an increased reaction temperature of $80^{\circ} \mathrm{C}$ delivered 6-bromo-4-(chloromethyl)-7-hydroxy-2Hchromen-2-one in only $10 \mathrm{~min}$. With the isolated product we then conducted the second step (hydrolysis) using water as a solvent and a reagent. It was immediately obvious that the reported reaction time of $12 \mathrm{~h}$ under reflux conditions could be substantially shortened by switching to sealed vessel microwave heating in a dedicated single-mode reac-

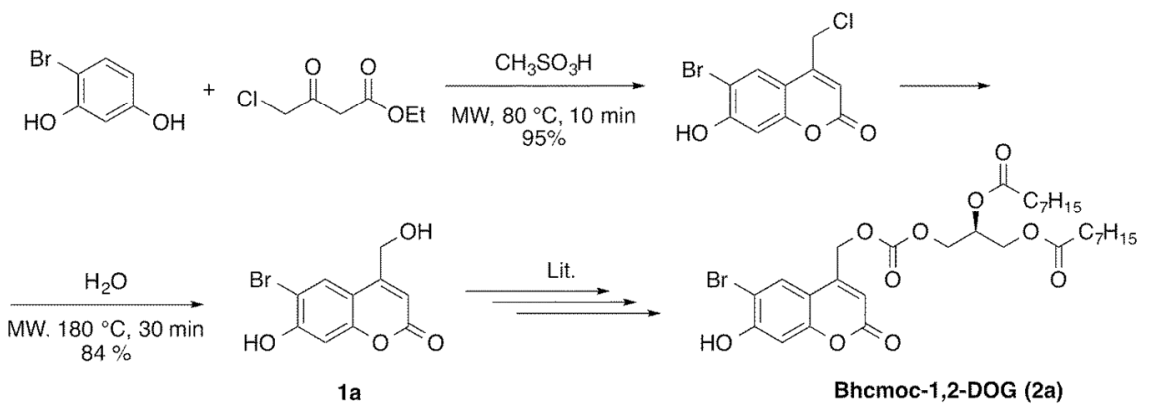

Figure 1 Synthesis of Bhcmoc-1,2-DOG. 
tor. At $180^{\circ} \mathrm{C}$ reaction temperature and only $30 \mathrm{~min}$ set reaction time, full conversion was achieved and $84 \%$ of pure coumarin 1a (Bhc-coumarin) were isolated after automated flash column chromatography. The following synthetic transformations were performed according to literature procedures and were not further optimized. The pure caged lipid (Bhcmoc-1,2-DOG, 2a) was obtained with the help of semi-preparative HPLC-chromatography and used in the biological experiments. Additionally, coumarins $\mathbf{1 b}-\mathbf{d}$ were prepared in similar fashion for the purposes of phototoxicity tests.

\section{Photouncaging of 1,2-DOG from Bhcmoc-1,2-DOG evokes TRPC3-mediated $\mathrm{Ca}^{2+}$ entry}

In a first step to test specificity of photouncaging-induced control of TRPC3 channel function, we compared the effects of photoreleased 1,2-DOG on $\mathrm{Ca}^{2+}$ entry into HEK293 cells at essentially low endogenous (HEK293 wild type) and enhanced expression of TRPC3. HEK293 cells were co-transfected with YFP-TRPC3 and genetically encoded red-emitting (R-GECO), a $\mathrm{Ca}^{2+}$ sensor, which does not interfere with coumarin emission. Prior to $\mathrm{Ca}^{2+}$ imaging experiments, the cells were loaded with $30 \mu \mathrm{mol} \mathrm{\textrm {L } ^ { - 1 }}$ of Bhcmoc-1,2-DOG caged lipid for approximately $10 \mathrm{~min}$. Two sequential boosts of UV illumination for $10 \mathrm{~s}$ duration elicited a large transient increase $\left(F / F_{0 \max }=2.2 \pm 0.12\right)$ in cytosolic $\mathrm{Ca}^{2+}$ levels as reported by changes in the intensity of the R-GECO $\mathrm{Ca}^{2+}$ sensor (Figure 2A). Next, we tested the sensitivity of this increase in cytosolic $\mathrm{Ca}^{2+}$ level to a common pharmacological tool that inhibits TRPC3 channels, SKF 96365 (Singh et al., 2010). When uncaging of 1,2-DOG was performed in the presence of $50 \mu \mathrm{mol} \mathrm{L} \mathrm{L}^{-1}$ SKF 96365, the intracellular $\mathrm{Ca}^{2+}$ signal was almost completely abolished $\left(F / F_{0 \max }=1.3 \pm 0.02\right)$ as illustrated in Fig- ure 2A. Furthermore, $100 \mu \mathrm{mol} \mathrm{L} \mathrm{L}^{-1}$ Bhcmoc-1,2-DOG evoked $\mathrm{Ca}^{2+}$ entry into TRPC3 overexpressing HEK293 cells of comparable extent $\left(\mathrm{F} / \mathrm{F}_{0 \max }=3.2 \pm 0.09\right)$ and this $\mathrm{Ca}^{2+}$ signal was again inhibited by $50 \mu \mathrm{mol} \mathrm{L}{ }^{-1}$ SKF 96365 (data not shown). Characterization of the effect of 1,2-DOG uncaging on $\mathrm{Ca}^{2+}$ levels in HEK293 wild type cells indicated a high level of specificity of the optopharmacological intervention, as effects on intracellular $\mathrm{Ca}^{2+}$ were hardly detectable $\left(F / F_{0 \max }=1.07 \pm 0.01\right)$ in HEK293 wild type control cells (Figure 2B). In a control experiment, HEK293 wild type cells were exposed to UV light in the absence of Bhcmoc-1,2-DOG. The increase in cytosolic $\mathrm{Ca}^{2+}$ level was comparable to the Bhcmoc-1,2-DOG $\left(30 \mu \mathrm{mol} \mathrm{L} \mathrm{L}^{-1}\right)$-induced $\mathrm{Ca}^{2+}$ entry (data not shown). Based on this result, we assume that the small increase in intracellular $\mathrm{Ca}^{2+}$ illustrated in Figure 2B is due to an artifact caused by UV illumination. Our results suggest that photouncaging of 1,2-DOG specifically activates TRPC 3 to elevate cytosolic $\mathrm{Ca}^{2+}$ level and may be suitable for optical control of TRPC 3 channels.

\section{Photouncaging of 1,2-DOG from Bhcmoc-1,2-DOG evokes a non-selective membrane conductance, inde- pendent of TRPC3 expression and masks TRPC3 chan- nel activity}

As a next step we tested specificity of the Bhcmoc1,2-DOG at the membrane conductance level. These experiments were considered essential in order to fill the gap regarding electrophysiological data on the control of TRPC channel activity by caged lipids using the patch clamp technique.

Consistently, we tested suitability of Bhcmoc-1,2-DOG $\left(30 \mu \mathrm{mol} \mathrm{L}{ }^{-1}\right)$ as a tool for photoactivation of TRPC3 by electrophysiological comparison in wild type HEK293 cells and in TRPC3-overexpressing HEK293 cells. After prein-
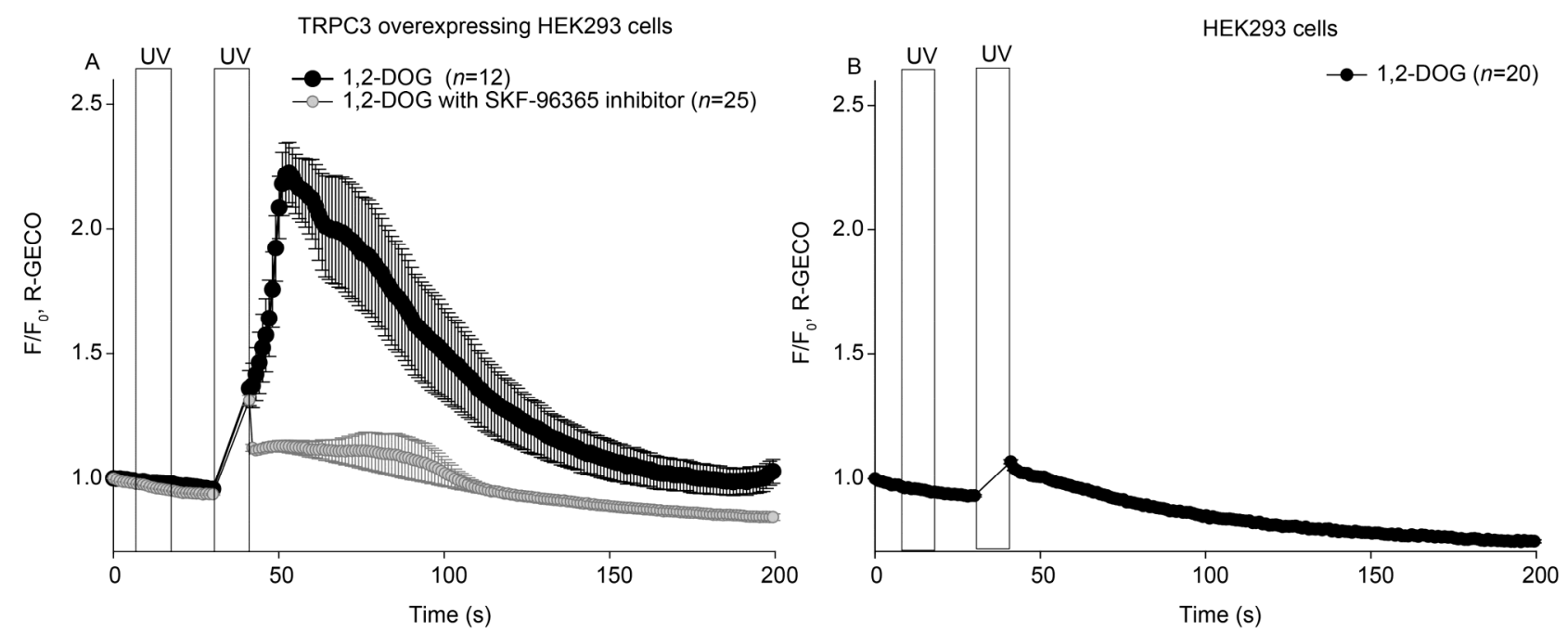

Figure 2 Live-cell imaging of photouncaging-induced changes in $\mathrm{Ca}^{2+}$ within HEK293 cells using a genetically encoded red-emitting Ca ${ }^{2+}$ sensor (R-GECO). A, $\mathrm{Ca}^{2+}$ transient during phototriggered uncaging of 1,2-DOG $(2 \times 10 \mathrm{~s}, 340 \mathrm{~nm}$, as indicated by UV) in TRPC3 overexpressing HEK293 cells (black line, $n=12$ ). Inhibition of 1,2-DOG induced $\mathrm{Ca}^{2+}$ entry by using $50 \mu \mathrm{mol} \mathrm{L}^{-1} \mathrm{SKF} 96365$ (grey line, $n=25$ ). $\mathrm{B}, \mathrm{Ca}^{2+}$ transient during phototriggered uncaging of 1,2-DOG $(2 \times 10 \mathrm{~s}, 340 \mathrm{~nm}$; UV) in wild type HEK293 cells $(n=20)$. Normalized intensity changes (mean \pm SE) are plotted as a function of time. 
cubation with Bhcmoc-1,2-DOG for 10 minutes, an initial boost of UV illumination (10 s) caused a small but distinct increase in membrane conductance of TRPC3 expressing cells as shown in Figure 3A. With the second UV illumination (10 s) clear light-induced currents were observed in TRPC3 overexpressing HEK293 cells displaying dependency on the concentration of caged lipid (30 and $100 \mu \mathrm{mol}$ $\mathrm{L}^{-1}$ ). These currents were persistent, lacked the typical transient nature of TRPC3 currents elicited by direct bath ap- plication of diacylglycerol (Figure 3B). Moreover, the currents were neither inhibited by $50 \mu \mathrm{mol} \mathrm{L}{ }^{-1}$ SKF96365 (Figure $3 \mathrm{~A})$ nor Ruthenium Red (10 $\mu \mathrm{mol} \mathrm{L}^{-1}$; not shown). To optimize TRPC3 current detection, we performed experiments in nominally $\mathrm{Ca}^{2+}$ free bath solution. This experimental setting resulted in larger inward currents in TRPC3 overexpressing HEK293 cells as compared to control HEK293 cells $(-23.1 \pm 1.6$ to $-8.7 \pm 2.6 \mathrm{pA} / \mathrm{pF}$; Figure $3 \mathrm{C})$. Of note, light-induced currents observed under
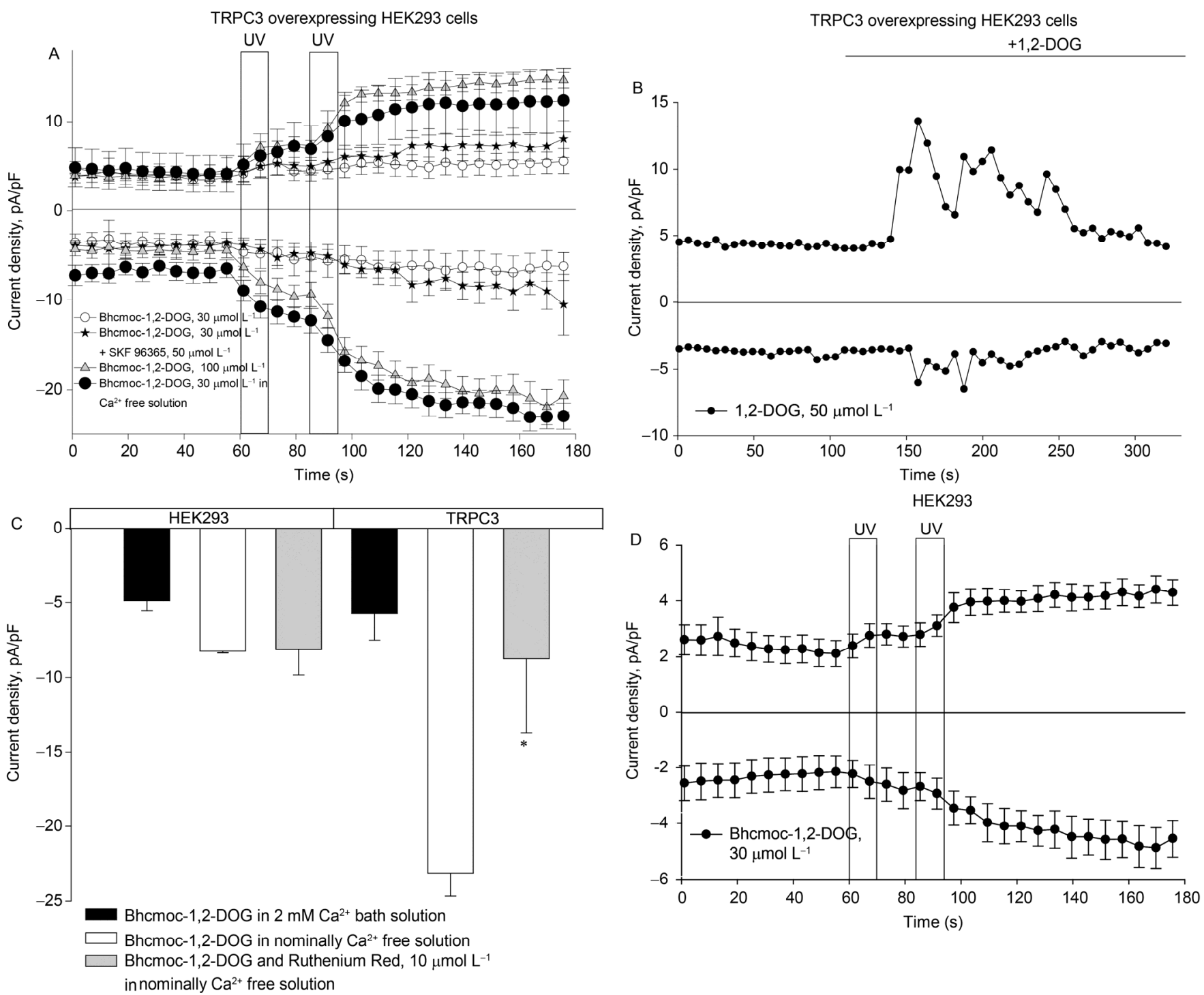

Figure 3 Patch-clamp characterization of photouncaging induced changes in membrane conductances of wild type and TRPC3 overexpressing HEK293 cells. A, Average time courses of current recordings in TRPC3 overexpressing HEK293 cells in the presence of Bhcmoc-1,2-DOG (30 $\mu$ mol $\mathrm{L}^{-1}$; $n=10$, open circles), Bhcmoc-1,2-DOG (100 $\mu \mathrm{mol} \mathrm{L}{ }^{-1} ; n=8$; grey triangles), Bhcmoc-1,2-DOG (30 $\left.\mu \mathrm{mol} \mathrm{L} \mathrm{L}^{-1}\right)$ and $\mathrm{SKF} 96365\left(50 \mu \mathrm{mol} \mathrm{L}{ }^{-1}\right.$; $n=10$, black stars), Bhcmoc-1,2-DOG in nominally $\mathrm{Ca}^{2+}$ free solution $\left(30 \mu \mathrm{mol} \mathrm{L}^{-1} ; n=4\right.$, black circles). B, Representative current recording in TRPC3 overexpressing HEK293 cells during bath application of 1,2-DOG $\left(50 \mu \mathrm{mol} \mathrm{L}{ }^{-1} ; n=4\right)$. C, Bar chart illustrating average inward current densities $(-90 \mathrm{mV})$ determined in control HEK293 cells and TRPC3 overexpressing HEK293 cells after photouncaging $(340 \mathrm{~nm}, 2 \times 10 \mathrm{~s})$ of Bhcmoc-1,2-DOG $\left(30 \mu \mathrm{mol} \mathrm{L} \mathrm{L}^{-1}\right)$ in $2 \mathrm{mmol} \mathrm{L}^{-1} \mathrm{Ca}^{2+}$

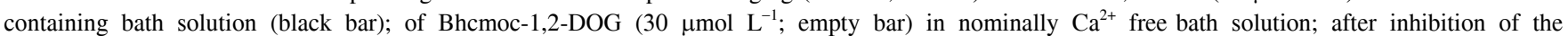
Bhcmoc-1,2-DOG-induced current with Ruthenium Red $\left(10 \mu \mathrm{mol} \mathrm{L}{ }^{-1}\right.$; gray bar $)$ in nominally Ca ${ }^{2+}$ free bath solution. The current density was calculated at 160 (empty bar) and 205 (gray bar) seconds. The asterisk denotes statistically significant differences versus the response obtained in TRPC 3 overexpressing HEK293 cells before and after Ruthenium Red application in nominally $\mathrm{Ca}^{2+}$ free bath solution. D, Average time courses of currents recorded in wild type HEK293 cells in the presence of Bhcmoc-1,2-DOG $\left(30 \mu \mathrm{mol} \mathrm{L}{ }^{-1} ; n=7\right)$. Mean \pm SE. 
these conditions still did not resemble the kinetic (transient) pattern typically evoked by directly applied 1,2-DOG (Figure 3B). Figure 3C shows a comparison of inward current densities induced by light application in control HEK293 cells and in TRPC 3 transfected cells pretreated with Bhcmoc-1,2-DOG employed in nominally free or $2 \mathrm{mmol} \mathrm{L}^{-1}$ $\mathrm{Ca}^{2+}$ containing bath solution. Statistically significant inhibition of inward current was observed with Ruthenium Red $\left(10 \mu \mathrm{mol} \mathrm{L}{ }^{-1}\right)$ only in TRPC3 transfected cells. However, light-induced currents were recorded in wild type (control) HEK293 cells in nominally free (not shown) and $2 \mathrm{mmol}$ $\mathrm{L}^{-1} \mathrm{Ca}^{2+}$ containing bath solution, indicating a TRPC3-independent membrane conductance was activated by photouncaging (Figure 3D).

\section{Photoreleased coumarin 1a is the molecular basis of} light-induced membrane conductances in HEK293 cells

We hypothesized that the Bhc-coumarin cage (coumarin 1a), as the photoreleased cage moiety, might cause the light-dependent cumulative increase in membrane conductance of HEK293 cells. This was further tested by current measurements in cells preincubated with coumarin 1a (30 $\mu \mathrm{mol} \mathrm{L} \mathrm{L}^{-1}$ ) for 10 minutes. Indeed, coumarin 1a-exposed, TRPC3 transfected HEK293 cells displayed clear UV light sensitivity (Figure 4A). Current-voltage relationship in coumarin 1a exposed cells closely resembled that measured
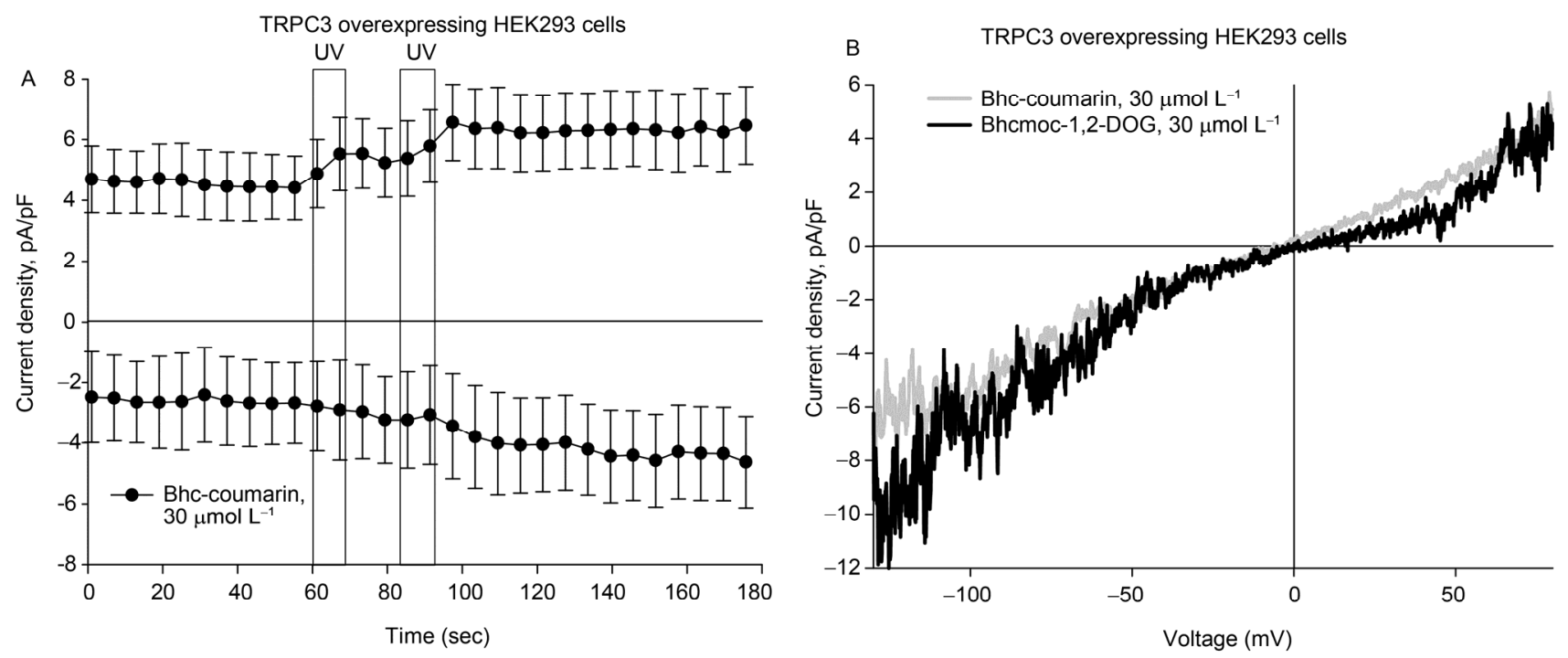

HEK293
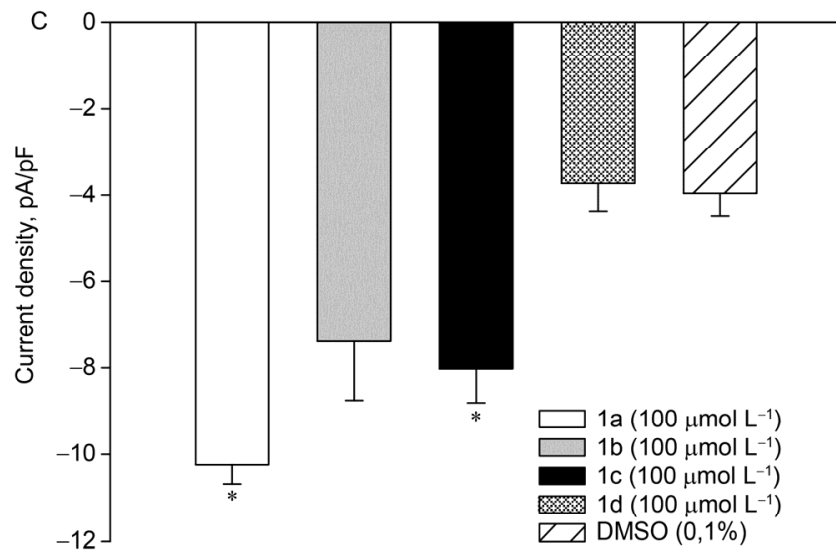<smiles>O=c1cc(CO)c2cc(Br)c(O)cc2o1</smiles>

1a<smiles>CN(C)c1ccc2c(CO)cc(=O)oc2c1</smiles>

$1 c$<smiles>COCOc1ccc2c(CO)cc(=O)oc2c1</smiles>

$1 b$<smiles>O=c1cc(CO)c2ccccc2o1</smiles>

$1 d$

Figure 4 Substituted coumarins cause phototoxicity, which gives rise to a non-selective membrane conductance independent of TRPC3 expression. A, Average time courses of current recordings in TRPC 3 overexpressing HEK293 cells treated with coumarin $1 \mathrm{a}\left(30 \mu \mathrm{mol} \mathrm{L} \mathrm{L}^{-1} ; n=5\right)$. B, Representative current to voltage relation for the "net" light-induced membrane conductance evoked in TRPC3 overexpressing HEK293 cells in the presence of Bhcmoc-1,2-DOG (30 $\mu \mathrm{mol} \mathrm{L} \mathrm{L}^{-1}$; black line) and Bhc-coumarin 1a as a control $\left(30 \mu \mathrm{mol} \mathrm{L}^{-1}\right.$; grey line). C, Bar chart illustrating average inward peak current densities (-90 mV) of control HEK293 cells induced with Bhc-coumarin (1a; $\left.100 \mu \mathrm{mol} \mathrm{L}^{-1} ; n=10\right)$, coumarin $\mathbf{1 b}\left(100 \mu \mathrm{mol} \mathrm{L}^{-1} ; n=10\right)$, coumarin $\mathbf{1 c}\left(100 \mu \mathrm{mol} \mathrm{L}{ }^{-1} ; n=4\right)$, coumarin 1d $\left(100 \mu \mathrm{mol} \mathrm{L}^{-1} ; n=5\right)$ and dimethyl sulfoxide (DMSO) $0,1 \%$ after stimulation with UV light $(340 \mathrm{~nm}, 2 \times 10 \mathrm{~s})$. The asterisks denote statistically significant differences versus the response obtained in control HEK293 cells in the presence of coumarin 1a, 1c and 1d (4-hydroxymethyl coumarin) was used as a control. D, The structures of various substituted 4-hydroxymethyl coumarin derivatives. Mean \pm SE. 
in response to Bhcmoc-1,2-DOG uncaging (Figure 4B). Similar coumarin 1a-dependent, light-induced responses were recorded in control HEK293 cells. To investigate further the origin of the TRPC-independent light-induced current, we tested coumarin compounds with different substituents 1b-1d in wild type HEK293 cells (Figure 4C). The observed data provide evidence for secondary photoactivation of coumarin derivatives $\mathbf{1 b}, \mathbf{1 c}$ as the basis of non-specific currents which were not observed in control experiments with DMSO 0,1\%. Importantly, the 4hydroxymethyl coumarin core $\mathbf{1 d}$ itself does not absorb UV light and therefore lacked any impact on the cells' membrane conductance. These experiments strongly suggest that the light-activated current initiated by photouncaging of the Bhcmoc-1,2-DOG was for its major part neither based on generation of a lipid mediator nor on the opening of TRPC3 channels. Although a minor component of the light induced TRPC3 current is anticipated to correspond to the TRPC3-mediated $\mathrm{Ca}^{2+}$ entry pathway, this $\mathrm{Ca}^{2+}$ conductance could not be detected above the background provoked by coumarin $\mathbf{1 a}$.

\section{DISCUSSION}

Although caged lipids are used increasingly in experimental biology and molecular physiology, these molecular tools were so far poorly characterized in electrophysiological studies, and their effects on membrane conductance are ill-defined. The lipid mediators such as diacylglycerols play a pivotal role in $\mathrm{Ca}^{2+}$ homeostasis. A common readout in studies on optical control of lipid-regulated $\mathrm{Ca}^{2+}$ transporters, channels or enzymes is intracellular free $\mathrm{Ca}^{2+}$ measured by fluorescent reporters. Coumarin is chemically versatile as a caging agent and has been employed for uncaging strategies of various second messengers (Mayer and Heckel, 2006). For example, coumarin caged cyclic guanosine monophosphate has been successfully used to control membrane currents in olfactory sensory cells (Furuta et al., 2004). Of note, in this study the caged messenger was directly administrated in to the cytoplasm via the patch pipette. This specific experimental setting minimizes non-specific effects of the caged-messenger and uncaging byproducts on the plasma membrane, which need to be considered especially when cells are preincubated with caged lipids. For coumarin caged lipids, specifically caged diacylglycerols, a high level of specificity in terms of TRPC channels have been suggested from experiments measuring intracellular free $\mathrm{Ca}^{2+}$ via common fluorescence probes. Our current study confirms a recent report about activation of TRPC3 channels by Bhcmoc-1,2-DOG (Nadler et al., 2013). We show clear inhibition of the photouncaging-induced $\mathrm{Ca}^{2+}$ signal by the TRPC3 inhibitor SKF 96365 and no significant light-induced changes in intracellular $\mathrm{Ca}^{2+}$ of wild type HEK293 cells. Nonetheless, our attempts to use Bhcmoc-1,2-DOG in electrophysiological experi- ments failed in terms of selective optical control of TRPC3 currents. This study is the first to report on coumarin-mediated photoactivation of a membrane conductance that masks TRPC3 channel currents. The electrophysiology data revealed a non-selective current with properties distinctly different than those of the lipid-activated TRPC3 was elicited in response to photouncaging of Bhcmoc-1,2-DOG. Up to $100 \mu \mathrm{mol} \mathrm{L} \mathrm{L}^{-1}$ of the caged lipid, photoactivated currents did not perfectly resemble the kinetic and current-voltage relationship of lipid-activated TRPC3 currents. Removal of $\mathrm{Ca}^{2+}$ from the external solution was used as intervention to promote TRPC3 currents according to previous reports previously (Rosker et al., 2004). This uncovered a TRPC3 expression dependent conductance, which was inhibited by Ruthenium Red down to the level observed in non-transfected HEK cells, indicating that TRPC3 is functional in these cells and responds to the lipid species released by photouncaging. Importantly, in the presence of physiological $\mathrm{Ca}^{2+}$ concentrations, the small TRPC 3 activity is effectively masked by an additional conductance. To further investigate the origin of this TRPC3-independent conductance, we hypothesized that coumarin as a photoreleased cage moiety might produce an off-target side effect. Indeed, similar currents were induced by UV light (340 nm) administration in the presence of the pure cage molecule (coumarin 1a), which is rapidly released during photouncaging of lipid from Bhcmoc-1,2-DOG. Coumarin by itself does not occlude UV light $(340 \mathrm{~nm})$, but certain derivatives absorb UV irradiation. Our electrophysiological data obtained with coumarin derivatives supported our hypothesis: photoactivation of currents in the presence of coumarins requires a molecular structure that allows UV light (340 nm) absorption. We performed a set of experiments, which revealed that photoactivated coumarin $\mathbf{1 a}-\mathbf{c}$ induced the nonselective currents in HEK293 cells. Coumarin 1d, which lacks UV absorption at $340 \mathrm{~nm}$ was found inactive (Figure 4C). Thus, we conclude that upon UV radiation of coumarin-caged lipid, the photoreleased coumarin moiety is capable of a phototoxic membrane effect. The chemical species underlying this effect remain elusive, but it is tempting to speculate about UV light-induced generation of membrane-active free radicals (Park et al, 1996).

Substituted coumarins have actually been employed as photosensitizers for decades (Zou et al., 2013). Psoralen, a naturally occurring coumarin derivative had been successfully used for clinical treatment of dermatological disorders (Mantulin and Song, 1973). It has been shown that psoralen can photoreact with unsaturated lipids and with molecular oxygen to produce active oxygen species such as superoxide and singlet oxygen that can cause damage to cell membrane (Park et al., 1996). In this context, we suggest that the substituted coumarins 1a-c, that are commonly used as photocleavable "cages" for various biologically active molecules, can give rise to phototoxic membrane effects in experimental situations typical for optopharmacology. 
Surprisingly, the currents initiated by UV light in the presence of phototoxic coumarins were not well correlated with rises in intracellular $\mathrm{Ca}^{2+}$ as single $10 \mathrm{~s}$ pulse of UV radiation was sufficient to generate currents while lacking any effect on cytosolic $\mathrm{Ca}^{2+}$. Thus, we conclude that the membrane conductance generated by UV light in the presence of coumarins was barely permeable for $\mathrm{Ca}^{2+}$. A series of pharmacological experiments using classical blocker of cation currents such as Ruthenium Red (data not shown) and SKF 96365 showed insensitivity of the coumarin-dependent conductance. Considering the ionic composition of the buffer solutions used in our electrophysiological experiments, conductances selective for $\mathrm{Na}^{+}$and $\mathrm{Cs}^{+}$as well as $\mathrm{Cl}^{-}$or divalents can be excluded as the respective equilibrium potentials are significantly different from reversal potential of the recordings, which varied from +4 to +11 $\mathrm{mV}$. Consistently, when $\mathrm{Cl}^{-}$in the bath solution was reduced from 148 to $2 \mathrm{mmol} \mathrm{L}^{-1}$ (replaced by gluconate), the reversal potential did not change significantly. When $\mathrm{Na}^{+}$ was replaced by N-methyl-D-glucamine (NMDG), the reversal potential shifted from $5.1 \pm 1.9$ to $-9.3 \pm 2.4 \mathrm{mV}$ (data not shown). Interestingly, this conductance does not allow for permeation of $\mathrm{Ca}^{2+}$ as photouncaging generated an exclusively TRPC3-dependent $\mathrm{Ca}^{2+}$ signal. Nonetheless, to that end, we cannot exclude that this conductance represents a rather nonspecific phototoxic leak condition of the plasma membrane The exact nature of the conductance associated with activation of coumarin-caged messengers remains to be determined in further detail.

Net inward currents initiated in TRPC 3 expressing cells by lipid uncaging in physiological ionic conditions were apparently in the range of a few $\mathrm{pA} / \mathrm{pF}$ and not clearly separable from the phototoxic membrane effects Nonetheless, recordings in nominally $\mathrm{Ca}^{2+}$ free solution allowed to detect the TRPC 3 response in the presence of coumarin. Although, the phototoxic coumarin effect qualitatively did not disturb $\mathrm{Ca}^{2+}$ signalling by TRPC3, it is anticipated that certain cellular processes may well be affected. Our findings suggest that results from optopharmacological application of coumarin-caged messengers have to be considered with particular care for the phototoxic effect of the released coumarin on membrane function.

\section{MATERIALS AND METHODS}

SKF 96365 was purchased from Enzo Life Science AG, Switzerland. 1,2-di- $O$-octanoyl glycerol was purchased from Sanova Pharma GmbH, Austria.

\section{Synthesis of 6-bromo-7-hydroxycoumarin-4- ylmethoxycarbonyl phototriggered 1,2-di-O-octanoyl glycerol (Bhcmoc-1,2-DOG)}

General remarks

${ }^{1} \mathrm{H}-\mathrm{NMR}$ spectra were recorded on a Bruker $300 \mathrm{MHz}$ in- strument. Chemical shifts $(\delta)$ were quoted in ppm referenced to the appropriate solvent peak. The letters $\mathrm{s}, \mathrm{d}$, $\mathrm{t}$, br are used to indicate singlet, doublet, triplet, and broad. Low-resolution mass spectra were obtained on a Shimadzu LC/MS-2020 (Japan) instrument using electrospray ionization (ESI) in positive or negative mode. Analytical HPLC (Shimadzu LC20) analysis was carried out on a C18 reversed-phase (RP) analytical column $(150 \mathrm{~mm} \times 4.6 \mathrm{~mm}$, particle size $5 \mu \mathrm{m}$ ) at $25^{\circ} \mathrm{C}$ using a mobile phase A (water/acetonitrile 90:10 (v/v)+0.1\% TFA) and $\mathrm{B}(\mathrm{MeCN}+$ $0.1 \% \mathrm{TFA}$ ) at a flow rate of $1.5 \mathrm{~mL} \mathrm{~min}^{-1}$. The following gradient was applied: linear increase from solution $30 \% \mathrm{~B}$ to $100 \% \mathrm{~B}$ in $8 \mathrm{~min}$, hold at $100 \%$ solution B for $2 \mathrm{~min}$. All solvents and chemicals were obtained from standard commercial vendors and were used without any further purification. Chromatography purification was done on an automated Biotage SP4 flash chromatography system. Analytically pure samples were obtained on a Shimadzu LC10 semi-preparative chromatography instrument.

\section{Microwave experiments}

Microwave-assisted reactions were carried out in Biotage Initiator 8 EXP 2.5 (Biotage AB, Sweden) single-mode microwave instrument producing controlled irradiation at 2.45 $\mathrm{GHz}$ in $20 \mathrm{~mL}$ cylindrical Pyrex microwave reaction vials. Reaction times refer to hold times at the temperatures indicated, not to total irradiation times. The temperature was measured with an IR sensor on the outside of the reaction vessel. All microwave experiments were carried out using magnetic stirring at a rate of $720 \mathrm{r} \mathrm{min}^{-1}$ unless otherwise stated.

\section{6-bromo-4-(chloromethyl)-7-hydroxy-2H-chromen-2-one}

A mixture of 4-bromoresorcinol (1 g, $5.29 \mathrm{mmol})$, ethyl 4-chloro-3-oxobutanoate ( $1.1 \mathrm{~mL}, 8.09 \mathrm{mmol}, 1.5$ equiv.), and methanesulfonic acid (8.6 mL, $132.27 \mathrm{mmol}, 25$ equiv.) in a $20-\mathrm{mL}$ Pyrex microwave vial, equipped with a magnetic stir bar, was capped with a Teflon septum, stirred for $10 \mathrm{~s}$ and subjected to microwave heating for $10 \mathrm{~min}$ (fixed hold time) at $80^{\circ} \mathrm{C}$ and subsequently cooled to $50^{\circ} \mathrm{C}$. The dark reaction mixture was poured in ice-water and stirred for half an hour. The desired product was obtained as an off-white solid $(1.46 \mathrm{~g}, 95 \%)$ by vacuum filtration after washing with water and dry. ${ }^{1} \mathrm{H}$ NMR (300 MHz, DMSO-d $\left.\mathrm{d}_{6}\right): \delta=11.56$ (Br s, 1H), 7.99 (s, 1H), $6.92(\mathrm{~s}, 1 \mathrm{H}), 6.48(\mathrm{~s}, 1 \mathrm{H}), 5.00(\mathrm{~s}$, 2H); LC-MS (pos. ESI), m/z: $289\left[\mathrm{M}\left({ }^{79} \mathrm{Br}\right)+\mathrm{H}\right]^{+}, 291$ $\left[\mathrm{M}\left({ }^{81} \mathrm{Br}\right)+\mathrm{H}\right]^{+}, \quad 330 \quad\left[\mathrm{M}\left({ }^{79} \mathrm{Br}\right)+\mathrm{MeCN}\right]^{+}, \quad 332\left[\mathrm{M}\left({ }^{81} \mathrm{Br}\right)+\right.$ $\mathrm{MeCN}]^{+}$.

\section{6-bromo-7-hydroxy-4-(hydroxymethyl)-2H-chromen-2- one (1a)}

6-bromo-4-(chloromethyl)-7-hydroxy-2H-chromen-2-one $(1.1 \mathrm{~g}, 3.80 \mathrm{mmol})$ in $10 \mathrm{~mL}$ of $\mathrm{H}_{2} \mathrm{O}$ in a 20 -mL Pyrex microwave vial, equipped with a magnetic stir bar, was capped 
with a Teflon septum, stirred for $10 \mathrm{~s}$ and subjected to microwave heating for $30 \mathrm{~min}$ (fixed hold time) at $180^{\circ} \mathrm{C}$ and subsequently cooled to $50^{\circ} \mathrm{C}$. After vacuum filtration and wash additionally with water, the desired product was obtained as off-white solid (861.4 mg, 84\%). ${ }^{1} \mathrm{H}$ NMR (300 MHz, DMSO-d ${ }_{6}$ ): $\delta=11.39$ (br s, 1H), 7.84 (s, 1H), 6.89 (s, $1 \mathrm{H}), 6.27(\mathrm{~s}, 1 \mathrm{H}), 5.61(\mathrm{t}, J=5.1 \mathrm{~Hz}, 1 \mathrm{H}), 4.69(\mathrm{~d}, J=3.6 \mathrm{~Hz}$, $1 \mathrm{H}) ; \mathrm{LC}-\mathrm{MS}$ (pos. ESI), $m / z: 271\left[\mathrm{M}\left({ }^{79} \mathrm{Br}\right)+\mathrm{H}\right]^{+}, 273$ $\left[\mathrm{M}\left({ }^{81} \mathrm{Br}\right)+\mathrm{H}\right]^{+}, \quad 312 \quad\left[\mathrm{M}\left({ }^{79} \mathrm{Br}\right)+\mathrm{MeCN}\right]^{+}, \quad 314 \quad\left[\mathrm{M}\left({ }^{81} \mathrm{Br}\right)+\right.$ $\mathrm{MeCN}]^{+}$.

All other compounds were prepared following literature procedures and showed analytical properties in good correlation to the reported data.

\section{Cell culture and transfection}

Human embryonic kidney 293 (HEK293) cells were cultured in Dulbeco's Modified Eagle Medium (DMEM high glucose with pyruvate, Invitrogen, USA) supplemented with $10 \%$ fetal bovine serum, streptomycin $\left(100 \mu \mathrm{g} \mathrm{mL}^{-1}\right)$, penicillin $\left(100 \mathrm{U} \mathrm{mL}^{-1}\right)$, L-glutamine $\left(2 \mathrm{mmol} \mathrm{L}^{-1}\right)$ and HEPES $\left(10 \mathrm{mmol} \mathrm{L}^{-1}\right)$ at $37^{\circ} \mathrm{C}$ and $5 \% \mathrm{CO}_{2}$. Cells were transiently transfected using FuGENE ${ }^{\circledR}$ HD Transfection Reagent (Promega, USA) according to the manufacturer's protocol. Briefly, $5 \mu \mathrm{g}$ of plasmid DNA encoding the appropriate sensor/fusion protein and $6 \mu \mathrm{L}$ transfection reagent were added to $200 \mu \mathrm{L}$ Opti-MEM ${ }^{\circledR}$ (Invitrogen) and mixed thoroughly. Transfection mixture was incubated for $15 \mathrm{~min}$ at room temperature and subsequently added to cells grown in $35 \mathrm{~mm}$-dishes. Cells were harvested and plated to cover slips $24 \mathrm{~h}$ after transfection. All experiments were performed either 24 or $48 \mathrm{~h}$ after transfection.

\section{Measurement of intracellular $\mathrm{Ca}^{2+}$ signaling}

Prior to experiment, HEK293 cells were transfected with either only genetically encoded red-emitting R-GECO or with R-GECO and YFP-TRPC3. Transfected cells were plated to cover slips $24 \mathrm{~h}$ after transfection. Cells were preincubated with $30 \mu \mathrm{mol} \mathrm{\textrm {L } ^ { - 1 }}$ Bhcmoc-1,2-DOG at room temperature for $10 \mathrm{~min}$ in imaging buffer $\left(137 \mathrm{mmol} \mathrm{L}^{-1}\right.$ $\mathrm{NaCl}, 5.4 \mathrm{mmol} \mathrm{L}{ }^{-1} \mathrm{KCl}, 10 \mathrm{~m}$ HEPES, $10 \mathrm{mmol} \mathrm{L}{ }^{-1} \mathrm{Glu}-$ cose, $1 \mathrm{mmol} \mathrm{L}{ }^{-1} \mathrm{MgCl}_{2}, 2 \mathrm{mmol} \mathrm{L}{ }^{-1} \mathrm{CaCl}_{2}$ ). Excitation light was supplied via a Polychrome II polychromator (TILL Photonics, Gräfelfing, Germany) and emission was detected by a Sensicam CCDcamera (PCO Computer Optics). Fluorescence intensity changes of R-GECO Ca ${ }^{2+}$ sensor was measured at $577 \mathrm{~nm}$ excitation and $632 \mathrm{~nm}$ emission wavelengths. Light stimulation was facilitated by using $340 \mathrm{~nm}$ excitation wavelengths for $10 \mathrm{~s}$. Digital image recordings were recorded and analyzed by using Axon Imaging Workbench (Axon Instruments, USA).

\section{Electrophysiology}

For electrophysiological measurements whole cell voltage clamp technique was used. Patch pipettes were pulled from thin-wall filament glass capillaries to a resistance of 2-4 $\mathrm{M} \Omega$. An inverted Microscope Axiovert 200 (Zeiss, Germany) was used to identify positively transfected cells by their green fluorescence when illuminated at $500 \mathrm{~nm}$. Whole-cell experiments were performed at room temperature using Axopatch 200B amplifier (Molecular Devices, USA) connected with a Digidata-1440A Digitizer (Axon Instruments). Currents were filtered at $3 \mathrm{kHz}$ by a 3 -pole Bessel filter and digitized with $8 \mathrm{kHz}$. Application of linear voltage-ramp protocols ranging from -130 to $+80 \mathrm{mV}$ (holding potential $0 \mathrm{mV}$ ) was controlled by Clampex 10.4 (Axon Instruments) software. Current densities at -90 and $+70 \mathrm{mV}$ were plotted against time and normalized by capacitance. Current-voltage relationships from -130 to $80 \mathrm{mV}$ were normalized by capacitance. Light stimulation was performed at 60 and $90 \mathrm{~s}$ for $10 \mathrm{~s}$ (UV, $340 \mathrm{~nm})$.

Standard pipette solution contained (in $\mathrm{mmol} \mathrm{L}^{-1}$ ): 120 cesium methanesulfonate, $20 \mathrm{CsCl}, 15 \mathrm{HEPES}, 5 \mathrm{MgCl}_{2}, 3$ EGTA titrated to $\mathrm{pH} 7.3$ with $\mathrm{CsOH}$. Patch clamp experiments were performed using extracellular solutions containing (in mmol L ${ }^{-1}$ ): $140 \mathrm{NaCl}, 10$ Hepes, 10 Glucose, 2 $\mathrm{MgCl}_{2}, 2 \mathrm{CaCl}_{2} \mathrm{pH}$ adjusted to 7.4 with NMDG. For nominally $\mathrm{Ca}^{2+}$ free experiments $\mathrm{CaCl}_{2}$ was excluded from the extracellular solution.

Before recording, cells were incubated with Bhcmoc-1,2DOG with/without SKF 96365 in the bath solution for 10 min at room temperature. 1,2-DOG or Ruthenium Red were applied into superfusion solution at 60 and $180 \mathrm{~s}$, respectively.

Data analysis and graphical display was performed using Clampfit 10.4 (Axon Instruments) and SigmaPlot 11.0 (Systat Software Inc.). Data are expressed as mean \pm SE. Student's two-sample $t$-test was used to assess statistical significance $(*, P<0.05$.).

Compliance and ethics The author(s) declare that they have no conflict of interest.

Acknowledgements This work was supported by the Austrian Science Fund (FWFW 1226-B18).

Fu, J., Gao, Z., Shen, B., and Zhu, M. (2015). Canonical transient receptor potential 4 and its small molecule modulators. Sci China Life Sci 58, 39-47.

Furuta, T., Wang, S.S., Dantzker, J.L., Dore, T.M., Bybee, W.J., Callaway, E.M., Denk, W., and Tsien, R.Y. (1999). Brominated 7-hydroxycoumarin-4-ylmethyls: photolabile protecting groups with biologically useful cross-sections for two photon photolysis. Proc Natl Acad Sci USA 96, 1193-1200.

Furuta, T., Takeuchi, H., Isozaki, M., Takahashi, Y., Kanehara, M., Sugimoto, M., Watanabe, T., Noguchi, K., Dore, T.M., Kurahashi, T., Iwamura, M., and Tsien R.Y. (2004). Bhc-cNMPs as either water-soluble or membrane-permeant photoreleasable cyclic nucleotides for both one- and two-hoton excitation. Chem Bio Chem 5, 1119-1128.

Givens, R., Rubina, M., and Wirz, J. (2012). Applications of p-hydroxyphenacyl (pHP) and coumarin-4-ylmethyl photoremovable protecting groups. Photochem Photobiol Sci 11, 472-488. 
Goeldner, M., and Givens, R. (2005). Dynamic Studies in Biology: Phototrigges, Photoswitches and Caged Biomolecules (Weinheim: WILEYVCH Verlag GmbH \& Co. KGaA).

Hagen, V., Kilic, F., Schaal, J., Dekowski, B., Schmidt, R., and Kotzur, N. (2010). [8-[Bis (carboxymethyl)aminomethyl]-6-bromo-7hydroxycoumarin-4-yl]methyl moieties as photoremovable protecting groups for compounds with $\mathrm{COOH}, \mathrm{NH} 2, \mathrm{OH}$, and $\mathrm{C}=\mathrm{O}$ functions. $\mathrm{J}$ Org Chem 75, 2790-2797.

Hess, G., Carpenter, B. K., Shembekar, V.R., and Chen, Y. (2007). Protecting group for carboxylic acids that can be photolyzed by visible light. USA Patent, US 2007/0243519A1.

Hofmann, T., Obukhov, A.G., Schaefer, M., Harteneck, C., Gudermann, T., and Schultz G. (1999). Direct activation of human TRPC6 and TRPC3 channels by diacylglycerol. Nature 397, 259-263.

Höglinger, D., Nadler, A., and Schultz, C. (2014). Caged lipids as tools for investigating cellular signaling. Biochim Biophys Acta 1841, 1085-1096.

Huang, X.P., Sreekumar, R., Patel, J.R., and Walker, J.W. (1996). Response of cardiac myocytes to a ramp increase of diacylglycerol generated by photolysis of a novel caged diacylglycerol. Biophys J, 70, 2448-2457.

Kamouchi, M., Philipp, S., Flockerzi, V., Wissenbach, U., Mamin, A., Raeymaekers, L., Eggermont, J., Droogmans, G., and Nilius, B. (1999). Properties of heterologously expressed hTRP3 channels in bovine pulmonary artery endothelial cells. J Physiol 2, 345-358.

Kim, Y.A., Ramirez, D.M.C., Costain, W.J., Johnston, L.J., and Bittman, R. (2011). A new tool to assess ceramide bioactivity: 6-bromo-7-hydroxycoumarinylcaged ceramide. Chem Commun 47, 9236-9238.

Lucas, P., Ukhanov, K., Leinders-Zufall, T., and Zufall, F. (2003). A diacylglycerol-gated cation channel in vomeronasal neuron dendrites is impaired in TRPC2 mutant mice: mechanism of pheromone transduction. Neuron 40, 551-61.

Mantulin, W.W., and Song, P.S. (1973). Excited states of skin-sensitizing coumarins and psoralens. Spectroscopic studies. J Am Chem Soc 95, 5122-5129.

Mayer, G., and Heckel, A. (2006). Biologically active molecules with a "Light Switch". Angew Chem Int Ed 45, 4900-4920.

Mentel, M., Laketa, V., Subramanian, D., Gillandt, H., and Schultz, C. (2011). Photoactivatable and cell-membranepermeable phosphatidylinositol 3,4,5-tris-phosphate. Angew Chem Int Ed Engl 50, 3811-3814.

Nadler, A., Reither, G., Feng, S., Stein, F., Reither, S., Müller, R., and Schultz, C. (2013). The fatty acid composition of diacylglycerols determines local signaling patterns. Angew Chemie Int Ed 52, 6330-6334.
Newton, A.C. (2010). Regulation of conventional and novel protein kinase $\mathrm{C}$ isozymes by phosphorylation and lipids. In Protein Kinase $\mathrm{C}$ in Cancer Signaling and Therapy, Current Cancer Research, M. G. Kazanietz, ed. (Berlin: Springer), pp. 9-23.

Ohanian, J., and Ohanian, V. (2001). Lipid second messenger regulation: the role of diacylglycerol kinases and their relevance to hypertension. $\mathrm{J}$ Hum Hypertens 15, 93-98.

Park, S.C., Goodrich, R.P., Yerram, N., Sowemino-Coker, S.O., Platz, M.S., and Aquila, B. (1996). Photodinamic inactivation of viral and bacterial blood contaminants with halogenated coumarin and furocoumarin sensitizers. USA Patent, WO 9608965A1.

Pelliccioli, A.P., and Wirz, J. (2002). Photoremovable protecting groups: reaction mechanisms and applications. Photochem Photobiol Sci 1, $441-458$.

Rosker, C., Graziani, A., Lukas, M., Eder, P., Zhu, M.X., Romanin, C., and Groschner, K. (2004). $\mathrm{Ca}^{2+}$ signaling by TRPC3 involves $\mathrm{Na}^{+}$entry and local coupling to the $\mathrm{Na}^{+} / \mathrm{Ca}^{2+}$ exchanger. J Biol Chem 279, 13696-13704.

van Rossum, D.B., Oberdick, D., Rbaibi, Y., Bhardwaj, G., Barrow, R.K., Nikolaidis, N., Snyder, S.H., Kiselyov K., and Patterson R.L. (2008). TRP_2, a lipid trafficking domain that mediates diacylglycerol-induced vesicle fusion. J Biol Chem 283, 34384-34392.

Singh, A., Hildebrand, M.E., Garcia, E., and Snutch, T.P. (2010). The transient receptor potential channel antagonist SKF 96365 is a potent blocker of low-voltage-activated T-type calcium channels. Br J Pharmacol 160, 1464-1475.

Subramanian, D., Laketa, V., Muller, R., Tischer, C., Zarbakhsh, S., Pepperkok, R., and Schultz, C. (2010). Activation of membranepermeant caged PtdIns(3)P induces endosomal fusion in cells. Nat Chem Biol 6, 324-326.

Suzuki, A.Z., Watanabe, T., Kawamoto, M., Nishiyama, K., Yamashita, H., Ishii, M., Iwamura, M., and Furuta, T. (2003). Coumarin-4-ylmethoxycarbonyls as phototriggers for alcohols and phenols. Org Lett 5, 4867-4870.

Tsien, R.Y., and Furuta, T. (2000). Protecting groups with increased photosensitivities. USA Patent, WO/00/31588.

Yang, C., and Kazanietz, M.G. (2003). Divergence and complexities in DAG signaling: looking beyond PKC. Trends Pharmacol Sci 24, 602-608.

Zou, Q., Fanga, Y., Zhao, Y., Zhao, H., Wang, Y., Gub, Y., and Wu, F. (2013). Synthesis and in vitro photocytotoxicity of coumarin derivatives for one- and two-photon excited photodynamic therapy. J Med Chem 56, 5288-5294.

Open Access This article is distributed under the terms of the Creative Commons Attribution License which permits any use, distribution, and reproduction in any medium, provided the original author(s) and source are credited. 